\title{
Apresentação de trabalho em eventos científicos: comunicação oral e painéis
}

\author{
João dos Santos Carmo \\ Universidade da Amazônia, Belém \\ Paulo Sérgio Teixeira do Prado \\ Universidade Estadual Paulista, Marília
}

\begin{abstract}
RESUMO
O presente artigo apresenta uma proposta de sistematização de duas modalidades de divulgação de pesquisa bastante comuns em eventos acadêmicos e científicos: a comunicação oral e o painel. Inicialmente discutir-se-á o significado e âmbito da comunicação científica, inserindo-a como uma das atividades do cientista. A divulgação dos trabalhos do pesquisador pode dar-se através de comunicação escrita, oral e mista. Em seguida serão feitas considerações conceituais e técnicas a respeito das modalidades de comunicação oral e por painel, abordando-se para cada uma delas os seguintes aspectos: definição; objetivos; características; cuidados e sugestões no planejamento e na execução das mesmas. Para cada modalidade apresentar-se-á um conjunto de orientações específicas que servirá de parâmetro para os interessados em aperfeiçoar suas apresentações. $\mathrm{O}$ artigo é voltado principalmente aos que dão os primeiros passos nos eventos acadêmicos e científicos e não tem a pretensão de esgotar todos os aspectos técnicos envolvidos na elaboração e divulgação através das modalidades aqui enfocadas.
\end{abstract}

Palavras-chave: divulgação científica; comunicação oral; sessão de painéis.

\begin{abstract}
Presentations on scientific events: oral communication and poster sessions

The present work exposes a proposal of systematization of two very common modalities in academic and scientific events: oral communication and poster sessions. First it will be discussed the meaning and scope of scientific communication, introducing it as one of the scientist activities. The spreading of the researcher studies can be organized both as written or spoken communication, and also mixing them. Next, some conceptual and technical considerations will be made on oral communication and poster, discussing the following aspects: definition, objectives, features, observations and suggestions about planning and execution. In each modality specific orientations are presented to everyone interested in improving their presentations. This article is especially directed to beginners in academic and scientific events. It has no pretension of being exhaustive concerning the technical aspects involved in the elaboration and scientific publicizing through the modalities emphasized here.
\end{abstract}

Keywords: scientific communication; oral communication; poster session.

\section{UM ESCLARECIMENTO INICIAL}

Gostaríamos de iniciar informando a você leitor que o assunto aqui tratado é algo sobre o qual nada encontramos na literatura mais recente. Portanto, o abordamos de um ponto de vista inteiramente pessoal, baseando-nos na nossa própria experiência, a qual temos acumulado ao longo de nossas participações em eventos científicos diversos e que inclui tanto apresentações propriamente ditas, como diálogos formais e informais com colegas, em torno do assunto. Esperamos que as considerações e sugestões que apresentamos lhe possam ser úteis e o ajudem a preparar e a fazer boas apresentações. É exatamente assim que sugerimos que você leia este artigo: como um conjunto de sugestões, jamais como receitas infalíveis.

\section{Ocasiões especiais para a divulgação científica}

A ciência, com uma atividade social, precisa ser divulgada, debatida, refletida. Uma das funções dos cientistas é exatamente a de possibilitar um amplo debate em torno de suas idéias, descobertas, teorias e proposições em geral. Daí a necessidade de se organizarem ocasiões especiais destinadas ao intercâmbio entre profissionais e à divulgação do conhecimento que produzem. Essas ocasiões podem ser acadêmicas ou, mais restritamente, científicas. Constituem-se nos congressos, simpósios, seminários, encontros, reuniões, os quais congregam comunidades de cientistas, pesquisadores, estudantes de vários níveis e outros interessados no debate e na divulgação científica.

Cada sociedade ou associação científica periodicamente promove encontros, mais amplos ou mais restritos em relação ao público, com o objetivo de oportunizar o contato entre os pares, sistematizar os avanços mais recentes em uma dada área, divulgar novos conhecimentos e traçar diretrizes e metas para 
os futuros empreendimentos numa determinada área do saber. De acordo com as normas e prazos estabelecidos pela organização do evento, os participantes submetem seus trabalhos, os quais, após apreciação e aprovação por comissões de especialistas, são expostos através de uma das modalidades básicas de apresentação: a comunicação oral e a exposição de painéis. Estas modalidades são implementadas de diversas maneiras e têm-se constituído, ao longo dos anos, em estratégias adequadas e facilitadoras da comunicação científica. Através delas, os participantes têm a oportunidade de divulgar seu trabalho, receber apreciações gerais, sugestões, críticas, além de possibilitar a ampliação do rol de interlocutores. Sem isso, dificilmente ter-se-ia condições de avaliar a qualidade, a repercussão e a aceitação do conhecimento produzido.

Atualmente, a forma mais valorizada de divulgação científica é a impressa, sobretudo por meio dos periódicos científicos especializados e dos livros. Os meios eletrônicos também têm ganhado importância crescente por proporcionarem uma agilidade impressionante na acessibilidade à informação a custos relativamente baixos. Contudo, o propósito do presente artigo é o de expor as principais características e modos de execução da comunicação oral e dos painéis. Para tanto, faremos considerações e sugestões que julgamos pertinentes a essas modalidades de divulgação, porém sem nos atermos a pormenores, particularidades e detalhamentos que variam a cada reunião científica e que são decididos pela organização geral e/ou pela comissão científica de cada evento.

\section{A divulgação como uma categoria de atividade científica}

Inicialmente, cumpre-nos esclarecer que a categorização aqui sugerida é, por assim dizer, provisória e foi proposta apenas para fins didáticos, não se tratando, portanto, de uma reflexão epistemológica sistemática.

Gostaríamos de frisar que o fazer científico integra-se por várias atividades. Apenas à guisa de exemplos, citemos: revisão de literatura, elaboração e execução de projeto de pesquisa, redação de relatório, publicação de resultados, apresentação em eventos etc. Note que algumas das atividades incluídas nos exemplos enquadram-se na categoria: divulgação científica. Esta, por sua vez, subdivide-se em duas subcategorias: oral e escrita, cada uma das quais contando com várias modalidades básicas de comunicação. Na primeira, temos exposição oral em mesas redondas, palestras, conferências, mini-conferências etc. Quanto à divulgação escrita, os mais conhecidos são os relatórios de pesquisa, livros e artigos científicos, ensaios teóricos, dissertações e teses, painéis, meios eletrônicos (sites na internet, CDs). Assim, trataremos a comunicação oral de pesquisas e a comu- nicação por painéis como modalidades pertencentes às subcategorias divulgação oral e divulgação escrita, respectivamente.

\section{Comunicação oral de pesquisa}

A comunicação oral é uma modalidade de divulgação científica realizada através de exposição verbal de tempo variável, com ou sem o auxílio de recursos didáticos audiovisuais e amplificadores de voz. O recurso predominantemente utilizado é, portanto, o próprio corpo do expositor, particularmente sua fala, seus gestos, expressões faciais, direcionamento do olhar e postura. Quanto à duração, as comissões organizadoras dos eventos científicos têm estipulado um tempo de apresentação em torno de dez minutos, seguido de breve debate e pedidos de esclarecimento em torno de cinco minutos. A decisão quanto ao tempo total da apresentação deve levar em consideração a quantidade de trabalhos a serem expostos numa determinada sessão de comunicações orais, bem como o tempo total da sessão.

A finalidade da comunicação oral é relatar sucintamente um estudo realizado, indicando os aspectos mais relevantes do mesmo, que são: considerações iniciais e objetivos do estudo, a metodologia empregada, os principais resultados obtidos, a discussão dos resultados e considerações finais. Estes aspectos são detalhados a seguir.

\section{CONSIDERAÇÕES INICIAIS E OBJETIVOS DO ESTUDO}

Dentro do que chamamos considerações iniciais, ou introdução, cabe fornecer algumas informações fundamentais, como o título do trabalho, nome(s) do(s) autor(es), filiação (instituição à qual vincula-se o autor ou autores), financiamentos (indicação da agência financiadora, quando for o caso), natureza do estudo (isto é, se é fruto de um trabalho de iniciação científica, de pesquisa de mestrado ou doutorado etc.). Após a apresentação inicial, o expositor deverá informar quanto ao tema abordado, estudos anteriores, problema ou questões norteadoras que direcionaram o estudo e, finalmente, o(s) objetivo(s) do trabalho. A capacidade de concisão é imprescindível para este item, uma vez que não há espaço nem necessidade de longas divagações em torno da literatura acerca do tema, nem é o momento para "aulas" ou demonstração de erudição por parte do expositor. Este deverá apenas situar a audiência quanto aos aspectos necessários à compreensão dos motivos que o levaram a traçar a pesquisa a ser apresentada. Em outras palavras, a proporção do tempo dedicado à introdução deve ser mí- 
nima, considerando-se que outros elementos deverão ser expostos.

Há modalidades com tempo maior de duração, como conferências, palestras etc., mas, via de regra, elas são realizadas por pesquisadores mais experientes e de maior projeção na comunidade científica. Em razão de ser este artigo destinado a um público iniciante, essas modalidades não serão abordadas.

\section{A metodologia empregada}

O percurso ou caminho metodológico traçado no estudo deve ser apresentado de forma clara e direta, sem necessidade de pormenorizar as fases ou etapas da coleta de dados, a não ser que determinados pormenores sejam imprescindíveis à compreensão e análise dos dados. De um modo geral, o percurso metodológico envolve a descrição da população estudada, as condições gerais em que se deu a coleta de dados (local, materiais empregados, testes e medidas padronizadas, variáveis relevantes do ambiente físico, social ou orgânicas etc.) e o procedimento empregado. Outros detalhes ficarão por conta das características do estudo e do tipo de pesquisa.

\section{Os resultados obtidos}

Faça uma descrição dos principais dados obtidos no estudo. Geralmente, o expositor utiliza linguagem visual apropriada como gráficos, tabelas, quadros, diagramas e outras ilustrações que facilitem a compreensão do público. Note que a ênfase deve incidir sobre os resultados principais, não sobre resultados secundários ou periféricos, os quais deverão ser guardados para uma ocasião oportuna.

\section{Discussão dos resultados}

Esta parte da exposição consiste na interpretação dos resultados obtidos, retomada dos objetivos gerais do estudo, comparação dos dados com a literatura da área em que o estudo está inserido. É, por assim dizer, o momento culminante da exposição, no qual o expositor enfatizará a contribuição trazida pela pesquisa ora apresentada. Alguns expositores, por economia de tempo ou por uma questão de estilo pessoal, preferem já ir discutindo os dados à medida mesma que os apresentam. Seja como for, a apresentação e a discussão dos resultados são fundamentais em qualquer exposição oral.

\section{CONSIDERAÇÕES FINAIS}

De um modo geral, nesta seção o expositor aproveita para dar indicações quanto à continuação do estudo a partir das prováveis lacunas que não foram preenchidas, e encerra a exposição agradecendo e colocando-se à disposição para eventuais questionamentos.

O leitor, provavelmente, questionará sobre a exigüidade do tempo disponível para a apresentação de tantas informações. Sem dúvida, esta é uma questão relevante e, possivelmente, o tempo em torno de dez a quinze minutos para as apresentações tenha sido proposto em razão do número crescente de trabalhos nos eventos científicos. Evidentemente, esta não é uma boa justificativa, uma vez que talvez haja necessidade de um maior controle ou rigor na aprovação dos trabalhos a serem apresentados. De qualquer forma, existem outras questões ligadas à duração de uma comunicação oral que exigem cuidados redobrados, como: planejamento, ensaio, uso adequado do tempo e dos recursos etc. Passaremos, a seguir, a abordar estes aspectos.

\section{PREPARANDO A APRESENTAÇÃO}

\section{Cuidados quanto ao planejamento}


Toda exposição precisa ser elaborada previamente. Embora esta seja uma afirmação um tanto óbvia, não nos parece demasiado repetitivo ressaltar que um bom planejamento da apresentação possibilita um bom desempenho durante a sua realização.

Um bom planejamento requer a previsão e delineamento dos seguintes aspectos: definição dos objetivos a serem alcançados, delimitação do tema a ser abordado, seleção do conteúdo a ser apresentado, distribuição adequada do tempo, definição dos recursos audiovisuais a serem empregados. Além disso, o planejamento deverá ser feito com uma antecedência suficiente, que proporcione condições adequadas para seleção dos recursos, evitando dificuldades de última hora (sobre a seleção dos recursos falaremos mais adiante).

Uma recomendação para os expositores iniciantes é para que apresentem o planejamento para pessoas mais experientes a fim de receber sugestões relevantes. Vale lembrar, sem qualquer intenção de ser irônico, que o planejamento deve ser escrito e não simplesmente pensado ou guardado na memória. Guardar na memória pode ser uma armadilha, pois freqüentemente nos esquecemos de alguns detalhes que podem ser determinantes na exposição. Por fim, devemos lembrar que, assim como planejamos nossas pesquisas, devemos também planejar sua apresentação.

\section{As vantagens do ensaio}

Concluído o planejamento, convém realizar alguns ensaios, isto é, simulações da apresentação. Elas funcionam como testes da adequação do planejamento e ajudam a evitar surpresas desagradáveis durante a exposição. Um bom ensaio pressupõe uma platéia seleta e atenta, disposta não somente a ouvir, mas também a colaborar através de sugestões, apreciações críticas, incentivos etc. Um primeiro ensaio permitirá a identificação de aspectos falhos a serem corrigidos, ao passo que os demais servirão para aprimorar ainda mais o trabalho.

Quantos ensaios? Não há um número padrão. Tudo parece sugerir que o acúmulo de experiência tende a deixar os indivíduos mais seguros e, portanto, com menor necessidade de ensaios. Por outro lado, os ensaios parecem auxiliar alguns indivíduos a adquirirem segurança. Outros, no entanto, preferem evitá-los por julgarem que eles geram mais ansiedade. De qualquer forma, a recomendação permanece válida tanto para os expositores mais experientes quanto para os iniciantes.

\section{Uso adequado do tempo}

A duração de uma apresentação deve seguir as normas previamente definidas para o evento. Infelizmente, às vezes presenciamos uma situação bastante constrangedora nas sessões de comunicação oral: alguns indivíduos extrapolam o tempo previsto e, com isso, prejudicam a exposição dos demais colegas. $\mathrm{O}$ último apresentador é, geralmente, o mais prejudicado, pois a audiência já está cansada, os colegas estão apressados, o coordenador da sessão está lutando contra o relógio devido às outras atividades que, possivelmente, ocorrerão no mesmo recinto.

É preciso, portanto, ter respeito aos colegas que ainda irão apresentar seus trabalhos e à platéia, que não compareceu para assistir somente à sua exposição. Pequenos atrasos são perfeitamente compreensíveis e perdoáveis, porém atrasos que extrapolam o aceitável refletem, por um lado, falta de planejamento e desrespeito aos demais e, por outro, falta de organização e controle da coordenação.

O aproveitamento do tempo, conforme já abordado, deve ser previamente planejado. Nesse planejamento será necessário distribuir o tempo de maneira adequada, proporcionalmente ao grau de importância de cada elemento da exposição. Conforme vimos em parágrafos anteriores, uma comunicação oral de pesquisa em geral está dividida em introdução, metodologia, resultados, discussão e considerações finais. Uma sugestão quanto à divisão proporcional do tempo seria: $10 \%$ para a introdução; $20 \%$ para a metodologia; 30\% para os resultados; $30 \%$ para a discussão; $10 \%$ para as considerações finais. Evidentemente esta divisão é, conforme salientamos, apenas sugestiva e, de modo algum, deverá ser entendida como uma regra a ser seguida às cegas. Cada apresentação tem suas nuances, suas características a serem ponderadas e consideradas no momento do planejamento.

Por um outro lado, temos comunicações orais de pesquisas teóricas. A divisão proporcional do tempo, neste caso, obedecerá ao esquema clássico de introdução, desenvolvimento e conclusão. Como as apresentações de pesquisas teóricas não seguem o mesmo padrão das pesquisas empíricas, cabe ao expositor dividir o tempo conforme suas necessidades e tendo em vista os objetivos de seu estudo.

\section{Uso adequado de recursos didáticos e equipamentos}

Afirmamos que o recurso predominante na exposição oral é o corpo do apresentador. Sua presença deve ser discreta, isto é, a gesticulação não deve ser exagerada de forma a direcionar a atenção da audiência mais para a teatralidade do expositor do que para o conteúdo da exposição. Da mesma forma, sua postura física não deve oferecer motivos para comentários jocosos. O olhar deverá ser direcionado ao público, não se prendendo em uma só pessoa, ao contrário, deverá percorrer toda a platéia. Este ponto merece atenção especial, pois o direcionamento consciente do 
olhar é bem mais difícil do que possa parecer. Basta uma sinalização qualquer, mesmo que sutil, como um meneio com a cabeça de um membro da platéia, para fazer que o olhar do apresentador fixe-se proporcionalmente por mais tempo naquela direção.

A altura da voz deverá ser adequada às dimensões do ambiente, o número de pessoas na audiência e a acústica do recinto. Procure informar-se sobre técnicas de uso da voz e outros recursos para obter os máximos resultados desse nosso precioso instrumento e preservação da saúde vocal. Os fonoaudiólogos têm dicas bastante simples, mas muito úteis e eficazes.

Recursos visuais. É bastante comum, e até esperado, que o expositor utilize recursos visuais e/ou audiovisuais para facilitar sua comunicação com o público. Dentre os recursos mais utilizados temos: retroprojetor, projetor de slides (atualmente em desuso), videocassete, DVD, projetor multimídia (datashow). Não é nossa intenção tratar detalhadamente qualquer um destes recursos em particular. Antes, preferimos destacar alguns aspectos relacionados ao seu uso. Assim, o expositor deve estar familiarizado com a operação do equipamento que terá à sua disposição.

Muitos de nós já assistimos a situações constrangedoras e, ao mesmo tempo cômicas, quando um determinado apresentador liga o retroprojetor e a imagem é projetada de ponta cabeça, espelhada, ou não enquadrada na tela; ou quando o expositor retrocede os slides ao invés de avançá-los; ou ainda, quando o expositor sequer sabe o que fazer com o videocassete ou com o datashow. Evidentemente, ninguém nasce sabendo operar esses recursos e não há nenhum demérito em perguntar como devem ser usados. O problema está em deixar isso para o momento da apresentação, pois corre-se o risco de não receber a ajuda esperada. Mais uma vez, portanto, ressaltamos a necessidade do planejamento e do ensaio como atividades que ampliam nossas possibilidades de êxito durante as apresentações.

Por um outro lado, precisamos ter o cuidado de não apresentarmos uma quantidade excessiva de informações numa mesma tela. Use o mínimo possível de informações escritas a fim de não criar uma espécie de concorrência entre sua fala e o que é projetado. O conteúdo da projeção deve ser um auxiliar, não um concorrente da exposição, um apoio visual ao que se está expondo.

Outro problema, encontrado freqüentemente, diz respeito à sincronia entre a fala do expositor e o conteúdo da tela. Algumas vezes projetam-se informações que não se relacionam ao que está sendo exposto, seja porque o expositor simplesmente esqueceu do recurso visual, seja porque não foi projetada a informação adequada no momento preciso. Possivelmente, este problema decorre de uma falta de planejamento ade- quado, da inabilidade do expositor, ou em razão de o aparelho estar sendo operado por outra pessoa, sem que tenha havido um acerto prévio entre expositor e operador acerca dos detalhes da apresentação. Mas não vá para o extremo oposto de simplesmente ler o que está escrito na sua projeção. Este é outro mau uso dos recursos. A audiência sabe ler, e muito bem. Ler o que está sendo projetado, além de tornar a apresentação cansativa, chata mesmo, subestima as pessoas que a estão assistindo.

Por mais clara que seja a exposição, a compreensão do ouvinte pode não corresponder exatamente àquilo que você quis dizer. Isso é perfeitamente natural e até esperado. Portanto, lembre-se: clareza nunca é demais. Por isso, ao preparar sua apresentação, tente colocar-se na perspectiva do ouvinte. Isso poderá ajudá-lo a prever possíveis dúvidas e má compreensão e, por conseguinte, também a dar à sua apresentação uma maior clareza.

Ao preparar suas projeções (transparências, slides, apresentações em datashow etc.), leve em conta as dimensões e as condições de iluminação do ambiente onde será feita a apresentação. Isso o ajudará a decidir-se sobre detalhes tais como o tamanho das letras e figuras e sobre as cores a serem utilizadas. Como nem sempre é possível obter-se essas informações com antecedência, vamos apresentar algumas sugestões gerais.

Já dissemos que uma projeção não deve conter uma quantidade excessiva de informações. Isso obviamente o obrigaria a "espremê-las" num espaço reduzido, usando letras em tamanho pequeno, o que dificultaria a decodificação e a compreensão das informações. Opte por letras grandes, por exemplo: Times New Roman tamanho 48 para títulos e 32 para textos. Quanto ao uso das cores, o máximo contraste possível é o preto sobre fundo branco. Mas se você preferir valorizar esteticamente sua apresentação usando cores, opte por usar cores claras para o segundo plano e escuras para o primeiro. Só faça o inverso se você tiver certeza de que a iluminação do ambiente pode ser reduzida a um nível próximo da ausência total de luz.

Não abuse de recursos gráficos como variação em demasia de tipos de letras e outros elementos como efeitos 3D, sombreamento, setas, formas geométricas etc. Use esses recursos com parcimônia e opte sempre pela simplicidade e o bom senso. Tente adotar um padrão. Isto é, use um mesmo tipo de letra em todas as telas. Você poderá adotar uma formatação especial para títulos, outra para subtítulos e uma terceira para o texto propriamente dito. Adote um padrão também para diagramas, setas, conectores e outros recursos gráficos. Sempre que possível, use a simetria (horizontal e vertical). Evite figuras assimétricas e linhas 
que se cruzam. Ao usar gráficos, como histogramas por exemplo, lembre-se que o efeito tridimensional pode conferir-lhes uma aparência atraente, mas a leitura é bem mais fácil sem esse efeito. Seja como for, tenha por princípio que se por um lado, uma apresentação mal cuidada expressa desleixo e pode comprometer a qualidade do conteúdo da apresentação, por outro, a estética perfeita não compensará um trabalho ruim.

Algumas recomendações adicionais. Recomendamos a chegada ao local da apresentação com alguma antecedência e uma checagem geral das condições. Isso inclui um teste. Ele permitirá verificar o funcionamento do equipamento e também se não há problemas decorrentes do uso de versões diferentes de um mesmo programa de computador, caso haja um disponível. E ainda, a depender das características do equipamento, ele pode não projetar sua apresentação exatamente como você a preparou. Em qualquer dos casos, as alternativas são: fazer as adequações necessárias ou ter à mão uma cópia da apresentação em transparências. A primeira delas não é fácil de ser implementada, pois você poderá não dispor de tempo suficiente e/ou equipamento necessário. Quanto à segunda, é a mais recomendável, mas certifique-se de haver retroprojetor disponível.

O uso de apontadores. Não fique de costas para a audiência. Não é de bom tom dar as costas para alguém. Mas, além das boas maneiras, há uma razão funcional para não fazer isso. Se você não estiver usando um microfone, falar de costas para a audiência dificultará a audição. Por isso, se você estiver usando um retroprojetor, lembre-se de que você pode apontar detalhes da projeção sobre a própria lente do aparelho. A sombra do objeto usado será projetada na tela e você poderá permanecer de frente para o público.

Se a projeção estiver sendo feita através de outro recurso, você poderá usar como apontador uma haste suficientemente longa (atualmente em desuso) ou um apontador a laser. Em qualquer caso, evite dar as costas para a platéia. Fique de perfil. E lembre-se, se usar apontador a laser, faça movimentos lentos, procurando fixar o facho de luz no ponto da tela a ser destacado. Movimentos rápidos e/ou confusos confundem as pessoas que o estão assistindo. Elas tentarão acompanhar o ponto luminoso, desviando a atenção da fala do expositor e sem se fixar na projeção.

Notou a importância de levar o planejamento a sério? Isso inclui informar-se sobre os recursos disponíveis e se haverá ou não o apoio de pessoas designadas para operá-los. Nem todos os eventos contam com recursos sofisticados. Ainda é comum que em algumas situações só se disponha do retroprojetor. Se você não estiver bem informado, correrá o sério risco de perder um tempo precioso preparando sua apresenta- ção no computador, gravando-a em uma mídia qualquer e depois não ter como usá-la. Isso é um desastre! Portanto, por via das dúvidas, prepare e leve com você transparências com o mesmo conteúdo do disquete, $\mathrm{CD}$ etc. E se houver alguém para auxiliá-lo na apresentação - seja um voluntário ou um profissional contratado - combine com ele os detalhes que forem importantes para o seu caso: o arquivo (ou arquivos) que você usará (caso disponha de um microcomputador), a ordem de apresentação das telas e/ou transparências etc. E na hipótese de haver um microcomputador disponível, é recomendável que você copie seus arquivos no disco rígido, pois isso permitirá ao equipamento funcionar com sua velocidade máxima, agilizando a apresentação e evitando alguns riscos comuns que se corre quando se usa equipamento desse tipo.

O uso do microfone. A maioria das pessoas, quando usa um microfone pela primeira vez, fica mais ou menos embaraçada e acaba fazendo algum comentário quanto à sua própria inabilidade ou pouca familiaridade com ele, desculpando-se. Isto é dispensável, toma tempo e pode ser evitado com uma boa simulação, como já sugerimos. Eis mais algumas dicas simples e úteis. Segure o microfone a uns $15 \mathrm{~cm}$ à frente da boca e com uma inclinação de aproximadamente $45^{\circ}$. Fale usando um tom natural. Não eleve o tom da sua voz, pois o microfone a amplificará por você. Esta é exatamente a função dele. Mas também não fale baixo demais, pois assim nem o próprio microfone terá como captar a sua voz para poder amplificá-la e ninguém o ouvirá com clareza.

Qualquer som ou ruído emitido pelo seu próprio corpo que não fizer parte da apresentação, deverá ser feito "fora" do microfone. Por exemplo, se houver alguém auxiliando-o com as projeções e essa pessoa estiver próximo a você, ao pedir para ela avançar a projeção, faça-o com o microfone afastado da boca. Afaste-o também se for inevitável tossir, espirrar, pigarrear etc.

Roteiro da exposição. Por fim, gostaríamos de ressaltar um recurso importante, mas freqüentemente negligenciado: uma folha de papel com o roteiro da apresentação em mãos. Dispor de anotações sobre a seqüência da apresentação ou o conteúdo da mesma poderá auxiliar o apresentador durante situações delicadas, como o esquecimento de informações ou dificuldades no seguimento dos passos da apresentação. Uma breve pausa para consultar as anotações já salvou muitas apresentações. Imprima um roteiro com os pontos principais do que vai apresentar. E use letras grandes para facilitar a leitura a uma certa distância, de modo que você não precise ficar a todo momento aproximando o papel dos olhos.

\section{Uso adequado da linguagem}


É extremamente importante a utilização de uma linguagem clara, objetiva, gramaticalmente correta e permeada da terminologia própria da área de conhecimento à qual vincula-se o trabalho. Não nos referimos a uma retórica exagerada, a uma fala prolixa, artificial. Na verdade, a linguagem deve ser simples, porém suficientemente correta e engajada nos padrões adotados pela audiência. Vale ressaltar que, para tanto, o expositor deverá apresentar um domínio razoável do conteúdo e da terminologia da sua área de atuação. Além disso, nunca será demais destacar o cuidado quanto ao uso de expressões viciadas, como "né", "é", "tá", dentre outras. Vícios de linguagem acabam por empobrecer a apresentação e deixam uma impressão negativa na audiência.

Um momento especialmente importante de uma comunicação oral é o do debate, no qual ocorrem as intervenções da platéia através de pedidos de esclarecimento, críticas, sugestões e comentários em geral. O expositor deverá estar atento a todas as falas, independentemente de seu conteúdo ou de quem esteja falando. É comum que o expositor fique especialmente atento às intervenções por autoridades no assunto abordado, porém, grandes contribuições podem surgir de ouvintes anônimos. Portanto, devemos valorizar cada intervenção. E a fim de não perdermos o "fio da meada" daquilo que está sendo dito por alguém, sugerimos que você faça anotações rápidas acerca dos principais aspectos levantados à medida mesma em que estes forem surgindo. Isso facilitará em muito a organização das respostas a serem dadas.

Qualquer intervenção é, a rigor, um importante feedback para o trabalho que acabou de ser apresentado. Por outro lado, é o momento de o expositor avaliar seu próprio desempenho. Assim, ele deve estar não só atento, mas sobretudo, receptível às críticas, questionamentos e sugestões. Absorver as críticas não é uma tarefa fácil nem tranqüila. Gostamos dos elogios e evitamos ou fugimos das críticas e dos destaques dados aos nossos erros. Porém, não há necessidade de responder a todas as críticas. Elas devem ser anotadas e deve-se indicar ao crítico que suas observações serão levadas em consideração. Além disso, pode ocorrer de não termos as respostas para algumas perguntas. Nada melhor, neste caso, do que dizer simples e abertamente que não dispomos daquela resposta no momento. Ao invés de fragilidade, esta atitude poderá comunicar honestidade e humildade, duas qualidades bastante valorizadas nos meios acadêmico e científico. Com isto, porém, não queremos significar que o pesquisador pode negligenciar seu preparo teórico. Ao contrário, este deverá preparar-se com esmero para a comunicação oral, prevendo, se possível, as questões mais comuns que podem surgir durante sua exposição.

\section{PAINÉIS}

\section{O que são?}

Os painéis enquadram-se na modalidade comunicação escrita, aludida no início. Dois termos têm sido utilizados como sinônimos: painel e pôster. Todavia, há que se diferenciar o significado de cada um. Por painel devemos entender uma modalidade de comunicação científica cujo veículo fundamental é o pôster. Fisicamente, o pôster nada mais é do que um cartaz contendo elementos gráficos (texto e ilustrações) que sintetizam o conteúdo do trabalho a ser apresentado.

As dimensões de um pôster variam de evento para evento. Em geral, o tamanho sugerido é de $90 \mathrm{~cm}$ de largura por $100 \mathrm{~cm}$ de altura. Uma técnica de confecção atualmente muito popular e talvez a mais utilizada, é a de impressão em banner. Mas também pode-se fazer uma composição com folhas impressas separadamente. Tanto num como noutro caso, os elementos gráficos são normalmente diagramados em computador através de programas específicos. Há diversas opções de softwares e recursos de impressão. Considere-as com cuidado para adequá-las à sua disponibilidade financeira. Algumas alternativas conferem ao trabalho uma excelente qualidade estética, mas são caras. Contudo, também é possível obter-se uma boa qualidade usando-se papel comum e um modelo simples de impressora a jato de tinta. Se você não tiver uma, certamente a instituição onde você estuda tem.

Você notou que estamos tratando de uma modalidade visual. Não exclusivamente, é claro; pois ela não dispensa a comunicação oral. Mas eminentemente visual. O pôster é afixado em local previamente determinado. Os visitantes o lêem e, quando julgam necessário, pedem esclarecimentos ao expositor. Quando isto ocorre, há um diálogo entre ambos. Normalmente, esse diálogo não se limita a duas pessoas, pois um pôster não é exposto sozinho, mas junto com muitos outros. E um número de visitantes circula entre os pôsteres. Em razão dessa particularidade, não há uma sequiência lógica na exposição, ou seja, o expositor poderá ater-se a apenas algum aspecto a cada vez que é solicitado, a depender da natureza da solicitação. Assim, ao contrário da comunicação oral, que usa elementos visuais como recursos acessórios, o painel é uma modalidade visual que se suplementa com o diálogo. Esse aspecto dialógico pode constituir-se em importante vantagem sobre a exposição oral, visto ter esta um caráter mais unidirecional.

\section{Como funcionam?}

Os pôsteres são expostos numa sessão denominada sessão de painéis, a qual constitui-se em uma exibição simultânea de pôsteres afixados em espaço previamente determinado e com um tempo de exposição limitado. Em suas linhas gerais, a proposta é possibilitar que os visitantes circulem por entre os pôste- 
res e optem por ler o conteúdo daqueles que mais lhes interessem, podendo interagir com o expositor através de pedidos de esclarecimentos, questionamentos, sugestões etc.

O expositor, por seu lado, pode ser o autor principal ou um dos autores do trabalho veiculado. Portanto, certifique-se de estar bem preparado para apresentálo. Sobre isso, temos algumas sugestões. Porém, antes de apresentá-las, julgamos importante situá-lo historicamente, acreditando que isso possa dar-lhe uma noção mais clara de como evoluiu a modalidade e de algumas de suas variantes atuais.

\section{Uma breve e despretensiosa história}

A sessão de painéis, na qual são apresentados os pôsteres, tem recebido tratamento diferenciado ao longo dos anos, de acordo com o que as comissões organizadoras dos eventos científicos julgam ser mais adequado. Tentativas são feitas através de implementação de variantes, de modo a tornar a sessão mais funcional e valorizada. Assim, podemos identificar uma certa evolução tanto no que diz respeito ao formato da sessão, quanto à sua dinâmica.

Até o final da década de 80 , tínhamos a seguinte configuração: os pôsteres ficavam afixados em um local que permitisse a circulação de pessoas; podia ser um salão ou até mesmo corredores. O tempo da sessão variava de aproximadamente duas a quatro horas, período no qual o expositor deveria permanecer presente para receber e dialogar com os visitantes. Designava-se um coordenador geral, que era incumbido de visitar cada painel e debater com o expositor. Ele também verificava se o pôster estava afixado em local apropriado e se o expositor estava presente ao lado do mesmo. Esta primeira variante era bastante cansativa para todos os envolvidos, principalmente por dois motivos: geralmente o local destinado à sessão de painéis era pouco adequado (iluminação e ventilação podiam ser inadequadas, não se dispunham cadeiras para os apresentadores etc.). Alguns pôsteres acabavam sendo pouco visitados, o que tinha um efeito desestimulante para o apresentador.

Uma forma alternativa encontrada foi diminuir o tempo das sessões, o que não reduziu muito as dificuldades; ao contrário, essa alteração fez com que o público se aglomerasse mais ainda em razão do tempo agora reduzido, o que algumas vezes impossibilitava a interação com o expositor e, até mesmo, a leitura do pôster.

Outra variante foi a permanência do pôster por um tempo mais prolongado, podendo variar de algumas horas até durante todo o evento, e a programação de um horário específico para que o expositor pudesse interagir com os visitantes. Este formato, presente até hoje em alguns eventos, livrou o expositor da cansati- va tarefa de ficar em pé ao lado de seu pôster durante um tempo demasiadamente longo, porém, de certa forma relegou a sessão de painéis a uma posição secundária.

Para evitar que o debate ficasse esvaziado, introduziu-se a figura do debatedor, o qual ficava responsável por visitar um número fixo e específico de pôsteres a fim de gerar discussão com o expositor e, em alguns casos, avaliar a qualidade do trabalho apresentado com vistas a uma eventual publicação.

Mais recentemente, uma variante bem sucedida tem sido a de promover sessões paralelas de painéis, cada sessão organizada por área de conhecimento e com um número limitado de pôsteres. Em cada sessão há um coordenador, que também faz o papel de debatedor. A principal inovação é que a sessão divide-se em dois momentos: primeiramente os pôsteres são visitados e, após um tempo previamente estipulado pelo coordenador, a platéia é convidada a assistir a uma breve exposição do apresentador, seguida de debates. Esta última variante leva a uma fusão entre a comunicação oral e a comunicação através de painéis, permitindo uma melhor apreciação do trabalho apresentado, bem como a valorização do mesmo.

Como se pode ver, há formatos diferenciados de sessões de painéis, porém a idéia central permanece a mesma, ou seja, a exposição de um cartaz (pôster) no qual se resume um trabalho e a presença de um expositor para esclarecimentos gerais sobre ele. As tentativas de tornar as sessões mais funcionais e valorizadas possivelmente têm por intenção superar uma noção amplamente difundida de que os painéis são utilizados para trabalhos de menor importância, para trabalhos produzidos por alunos de graduação ou recém ingressos na pós-graduação. Esta noção é altamente prejudicial e talvez esteja aí a gênese da pouca valorização dada por alguns aos painéis. Feitas essas considerações, passemos aos aspectos referentes à elaboração de pôsteres e à conduta do apresentador durante a sessão de painéis.

\section{O que fazer?}

Ao elaborar seu pôster, considere seriamente aquele que é provavelmente um dos maiores limitadores de sua eficácia enquanto meio de comunicação científica: o contexto no qual ele é exposto. O que ocorre normalmente numa sessão de painéis é que há uma quantidade considerável de trabalhos sendo apresentados simultaneamente, uma grande circulação de pessoas e o inevitável burburinho que isso provoca. Ou seja, os interessados têm de lidar com um grande volume de informações e em condições nas quais muitos estímulos concorrem para desviar-lhes a atenção. Além disso, a disposição do pôster é tal que requer que o interessado o leia em pé, numa posição 
pouco confortável e cansativa. E ainda, para acessar às informações dispostas nas partes inferiores, o leitor deverá agachar-se ou curvar-se. Horrível! Observe que todas essas condições podem facilmente induzir desvios do assunto principal, o que recomendamos veementemente seja evitado.

\section{Considerações sobre os elementos gráficos}

Em razão de tudo o que se expôs até aqui, o princípio fundamental a nortear a elaboração de um pôster é: pouco texto, muita ilustração. Considerando tratarse de um recurso eminentemente visual, a idéia é tornar a apresentação o mais intuitiva possível. Como se faz isso?

Aspectos harmônicos. Cores berrantes são pouco atraentes. A distribuição das cores deve ser harmônica e garantir um bom contraste. A cor do fundo não deve competir com a dos elementos colocados em primeiro plano. Imagine um pôster com fundo amarelo e letras brancas, ou letras na cor preta sobre um fundo azul escuro! A leitura se tornaria difícil, cansativa e, como resultado, o pôster seria pouco visitado. Por um outro lado, ultimamente temos verificado uma verdadeira disputa em torno da dimensão estética. Pura banalidade. Nada mais infantil. O que realmente qualifica um bom trabalho é o seu conteúdo e a clareza com que ele é apresentado. Nunca é demais lembrar que a simplicidade (não simplismo!) deverá ser o toque principal em qualquer comunicação científica.

Distribuição dos elementos. $\mathrm{Na}$ parte superior dispõe-se o cabeçalho com as seguintes informações: título do trabalho, nomes dos autores acompanhados das respectivas afiliações institucionais e, muito importante, a indicação das agências financiadoras, quando for o caso. Um bom título sintetiza todo o trabalho (lembre-se de que você tem pouco espaço). Por isso, ele é um elemento fundamental e deverá aparecer em destaque. Abaixo, colocam-se os nomes dos autores, sublinhando-se o do que desempenhará a função de apresentador. Em alguns casos, solicita-se a indicação da localização geográfica da instituição (cidade, estado, país). Além dessas informações iniciais, sugerimos que sejam acrescentados os endereços eletrônicos dos autores.

A seguir, apresenta-se o corpo principal do trabalho que, em linhas gerais, compõe-se de introdução, desenvolvimento e conclusão. O que conterá cada um desses elementos variará de acordo com a natureza do trabalho e suas particularidades. As considerações já apresentadas anteriormente repetem-se aqui. Outras mais específicas para a modalidade serão desenvolvidas.

Faça o possível para dispor o texto na forma de tópicos e use frases curtas, porém, informativas e gramaticalmente corretas. Isso possibilitará a todos o conhecimento daquilo que é essencial no seu trabalho. A inclusão de muitos detalhes é perfeitamente pres- cindível. Nas condições de apresentação descritas, poucas serão as pessoas dispostas a examiná-los. E se eles forem excessivamente numerosos, isso dificultará ao leitor discriminar entre o que é relevante e o que é secundário. Já o uso adequado do texto facilitará o conhecimento das informações essenciais sobre o trabalho. Quem estiver realmente interessado em aprofundar-se em alguns detalhes, o fará através de perguntas apresentadas diretamente a você.

Como a leitura é, em geral, feita por mais de uma pessoa ao mesmo tempo, é comum vermos um pequeno aglomerado de visitantes em torno de um pôster tentando ler as informações nele contidas. Há, então, a necessidade de considerar o tamanho e o tipo da fonte (letra) a ser usada. Se considerarmos que um leitor

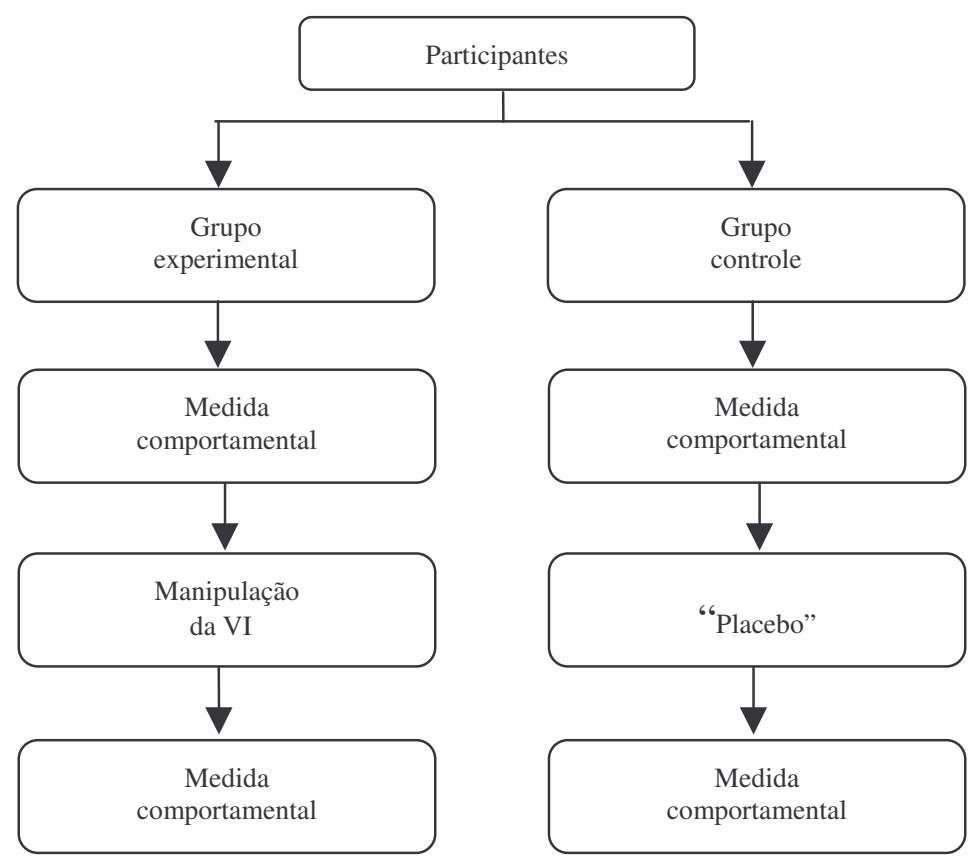

Figura 1: Exemplo de um diagrama esquemático para ilustrar um procedimento hipoté tico com delineamento experimental usando grupos de participantes (experimental e de controle).

comum pode ler sem dificuldades palavras escritas com letra do tipo Times, tamanho 24, a cerca de um metro e meio de distância, poderemos usar esta medida como padrão, variando-a para mais ou para menos de acordo com a função específica do texto: título (do próprio trabalho, de figuras, tabelas etc.), subtítulos, notas explicativas etc. Evite espaços muito reduzidos entre linhas e entre letras. O espaçamento deve ser suficiente para facilitar a fluidez da leitura.

Use diagramas, fluxogramas, esquemas enfim, que sejam razoavelmente auto-explicativos e possam substituir da forma mais eficiente possível a descrição verbal/textual de procedimentos e/ou outros aspectos de seu trabalho. Apenas à guisa de exemplo, apresentamos na Figura 1 uma situação hipotética em que um pesquisador em psicologia tivesse usado um delinea- 
mento de pesquisa usando grupos experimental e de controle para testar os efeitos de uma variável inde-

Obviamente a Figura 1, em particular, apresenta um diagrama muito simplificado e genérico. Informações adicionais poderiam constar em texto, na forma já sugerida, e/ou no próprio diagrama. O número de participantes, sua faixa etária e outras informações são algumas possibilidades. Na linha sob o retângulo rotulado como "Participantes", poderia constar a inscrição: "Divisão aleatória", para informar que os membros dos grupos experimental e de controle foram designados aleatoriamente. Em lugar de "Medida comportamental", os retângulos correspondentes poderiam conter o nome do teste específico empregado, se fosse o caso. Igualmente, no lugar de "Manipulação da VI", poderia constar uma palavra ou sentença descrevendo sucintamente o procedimento, ou que aludisse a algo melhor descrito textualmente. Os retângulos correspondentes aos grupos experimental e de controle poderiam ser desenhados em cores distintas. Um histograma apresentando os dados usaria as mesmas cores, facilitando a correspondência para o leitor.

Ilustrações devem conter um título próprio (veja o exemplo da Figura 1). Quadros e tabelas levam o título acima, ao passo que gráficos, diagramas, fotos etc., têm o título disposto abaixo da figura. O tamanho e o tipo de fonte poderão ser menores (em tamanho 18 , por exemplo) a depender da necessidade e da quantidade de informações contidas nas figuras.

\section{A postura do apresentador}

Em primeiro lugar, é indispensável que se compareça ao recinto com certa antecedência (dez minutos, em geral, são suficientes), pois isto facilitará afixar o pôster e apresentar-se ao coordenador da sessão, evitando atrasos e outras inconveniências. O pôster só deverá ser retirado após autorização do coordenador, ou conforme instruções da comissão organizadora. Temos presenciado ocasiões em que o expositor retira seu pôster imediatamente após a apresentação, ou até mesmo antes do encerramento da sessão, sem qualquer justificativa. Estas são atitudes deselegantes e de profundo desrespeito e desconsideração ao caráter coletivo de uma sessão de painéis e da ciência como um todo.

Em segundo lugar, considerando que o expositor pode ser um co-autor, é fundamental que ele esteja bastante familiarizado com o trabalho, de modo a estar suficientemente preparado para responder a indagações e apresentar detalhes ulteriores quando estes forem requeridos. Além disso, é absolutamente imprescindível que se assuma uma postura discreta. Haverá leitores muito interessados, alguns que visitam o painel por mera curiosidade e outros que poderão até demonstrar um certo desinteresse. Portanto, a dis- pendente (VI) qualquer sobre um determinado evento comportamental, a variável dependente (VD) ${ }^{1}$.

crição é a melhor atitude para deixar o visitante plenamente à vontade, respeitando sua individualidade. Obviamente, o visitante será recebido com o devido respeito, sem qualquer desmerecimento de suas apreciações, perguntas e sugestões, quer estas sejam ou não relevantes, quer sugiram conhecimento ou a ausência dele.

Outro aspecto importante relacionado à postura, diz respeito à disponibilidade para a ampliação de intercâmbios com a comunidade científica. Algumas providências simples e úteis sinalizarão para o público sua disposição para compartilhar informações e conhecimento. Tenha em mãos cópias reduzidas do pôster e cartões de visita com seus dados para eventuais contatos futuros. Quanto ao resumo, se você está apresentando seu trabalho significa que anteriormente você o submeteu e ele foi aceito. Logo, ele encontra-se publicado nos anais do evento e é de fácil acesso a todos. Por conseguinte, cabe a você decidir sobre preparar ou não cópias do resumo para serem distribuídas aos interessados. Adicionalmente, é possível que você disponha de um texto completo sobre o trabalho (seja na forma de relatório para uma agência de fomento e/ou para o seu orientador, ou um texto submetido para publicação ou já publicado num periódico etc.). Considere a possibilidade de também distribuir cópias dele. Finalmente, embora possa parecer um pouco de preciosismo, é recomendável ter um bloco de anotações para o registro de informações de interesse fornecidas por visitantes, sugestões de bibliografia etc. Essas são formas de se ampliar a interação com um público certamente privilegiado, a qual pode resultar num intercâmbio muito produtivo e até mesmo em novas parcerias.

Há situações em que mais de um autor estão presentes. Em casos assim, uma atitude de cooperação e de divisão de responsabilidades redundará num desejável e salutar revezamento. Isso possibilitará a todos experienciarem o papel de expositor e também que tomem conhecimento de outros trabalhos de seu interesse. Ademais, esta medida reduz o tempo individual de exposição, tornando-a menos cansativa e, ao mesmo tempo, ampliando o tempo disponível de cada um para uma participação mais intensa no evento.

\section{CONCLUSÃO}

Neste trabalho, propusemo-nos a apresentar considerações e sugestões julgadas úteis para um público composto principalmente por aqueles que se iniciam nos meandros do fazer científico. Apresentamos as modalidades de comunicação de pesquisa oral e por painéis como atividades científicas. Sobre cada uma 
apresentamos definições conceituais e orientações. Não tivemos a pretensão de ser rigorosos nem exaustivos, fosse do ponto de vista conceitual ou técnico. Quisemos apresentar-lhe um quadro real e ajudá-lo a preparar-se praticamente para ele. Esperamos ter-lhe ajudado. Agora, é com você.

Aceito: 10/05/2005

Bom trabalho!

\section{Nota:}

1 Note que o exemplo tem a finalidade exclusiva de ilustrar o uso do diagrama como recurso gráfico para substituir a descrição verbal/textual. Recomendamos ao leitor interessado em metodologia de pesquisa que procure livros sobre o assunto, adequados à sua área de atuação.

\section{Sobre os autores:}

João dos Santos Carmo: Psicólogo, Doutor em Educação pela Universidade Federal de São Carlos.

Paulo Sérgio Teixeira do Prado - Pedagogo, Doutor em Psicologia Experimental pela USP. Endereço para correspondência: Faculdade de Filosofia e Ciências - UNESP, Campus de Marília - Departamento de Psicologia da Educação - Av. Hygino Muzzi Filho, 737 Campus Universitário - 17525-900. Marília, SP - Tel.: (14) 3402-1300, Ramal 1371 - Endereço eletrônico: pradopst@ marilia.unesp.br. 